\title{
Entre jalecos, bisturis e a arte de fazer política
}

\section{Lab coats, scalpels, and the art of politics}

\author{
Fernanda Rios Petrarca ${ }^{i}$ \\ i Professora, Departamento de Ciências Sociais/ \\ Universidade Federal de Sergipe. \\ Aracaju - SE - Brasil \\ orcid.org/0000-0003-1351-3043 \\ f.petrarca@hotmail.com
}

Recebido em 17 out. 2017.

Aprovado em 3 jan. 2018.
PETRARCA, Fernanda Rios. Entre jalecos, bisturis e a arte de fazer política. História, Ciências, Saúde - Manguinhos, Rio de Janeiro, v.26, n.2, abr.-jun. 2019, p.573591.

\section{Resumo}

$\mathrm{O}$ artigo analisa as condições sociais e históricas de desenvolvimento da medicina como espaço de atuação profissional e domínio sobre determinado território ocupacional, no estado de Sergipe, das primeiras décadas do século XX aos anos 1960. Uma das principais constatações da investigação é a de que o processo de consolidação da medicina deve ser compreendido como parte das mudanças que nortearam a reestruturação das elites agrárias locais para evitar o declínio de sua condição. A forte rivalidade produzida no interior das parentelas e sua fragmentação, decorrente dos conflitos, conduziram a expansão dos vínculos e um direcionamento para os laços produzidos a partir do universo profissional.

Palavras-chave: medicina; política; profissão; parentela; famílias.

\section{Abstract}

The article analyzes the social and historical conditions of the development of medicine as a space for professional activity and domination of a specific occupational field in the state of Sergipe, from the early decades of the twentieth century to the 1960s. One of the main findings is that the process of consolidation in medicine should be understood as part of the changes that guided the restructuring of local agrarian elites to avoid their own decline. The strong rivalry produced within this kinship and consequent fragmentation resulting from conflict led to the expansion of ties and specific targeting for the connections produced in the professional world.

Keywords: medicine; politics; profession; kinship; families. 
$\mathrm{E}$ ste artigo tem como objetivo analisar as condições sociais que se tornaram fundamentais para que a medicina se consolidasse como espaço de atuação profissional, conquistando um domínio sobre determinado território ocupacional. O universo empírico que serve de base para o estabelecimento dessas discussões é o estado de Sergipe, e uma das questões centrais da investigação é a de que o investimento no projeto profissional compôs as estratégias de renovação dos grupos dirigentes, dos quais os médicos participavam.

O recorte temporal se estende das primeiras décadas do século XX até meados da década de 1970, momento em que se observam os movimentos de maior consolidação da medicina por meio das associações profissionais e da intensificação do papel dos hospitais na formação do saber e da autoridade médicas. Esse é o período em que os profissionais realizaram um forte trabalho de expansão, domínio e controle sobre as práticas de cura a partir do investimento, fundamentalmente, em duas frentes: criação de instituições/associações que os agrupassem e os reunissem e investimento nos vínculos políticos manifestados na ocupação de cargos no estado.

Para os autores vinculados à chamada corrente sociológica das profissões, como Wilensky (1964), Abbott (1988) e Freidson (2007), o ofício médico se tornou o ícone de um projeto profissional bem-sucedido a partir de um intenso controle sobre um espaço de atuação. As condições de realização desse projeto envolveram a reivindicação do monopólio da cura, o poder de definir o que é doença e a forma como tratá-la, bem como o direito exclusivo de exercer o ofício, impedindo dessa forma que curandeiros e outros praticantes da antiga arte de curar concorressem com os médicos.

Tal condição foi adquirida, de um lado, por meio do investimento acadêmico e treinamento técnico capaz de fazê-la distinguir-se dos demais curandeiros, tão procurados durante o século XIX e meados do XX por grande parte da população. A unificação do treinamento técnico, a capacidade de resolver problemas práticos - já que se trata de uma "profissão de consulta" (Freidson, 2007) -, assim como o controle do conteúdo e da forma de desempenhar o trabalho se tornaram essenciais para o progressivo afastamento dos práticos da cura. Tais condições contribuíram para atrair a confiança da população e criar a crença na competência. De outro lado, dependeu de um conjunto de forças externas, tais como mudanças técnicas, intervenção do Estado, modificações na demanda e investimentos em outros espaços sociais, sobretudo na política, para conquistar o controle sobre um território (Wilensky, 1964). O papel do médico na resolução de problemas públicos, a criação de espaços institucionais (hospitais, departamentos de saúde, associações) e a pretensão a ser reconhecidos como experts foram em grande parte resultado das relações e alianças estabelecidas com o Estado e as elites políticas (Abbott, 2003; Champy, 2009).

Nesse sentido, a relação com os grupos dominantes, entre outros elementos como vimos acima, tem sido apresentada como uma das estratégias fundamentais mobilizadas pela medicina para o estabelecimento de um monopólio no mercado de cura e para construção de um projeto profissional. Para apreender a relação entre a profissionalização da medicina e a reconfiguração das elites, privilegiamos três frentes principais de investigação. Primeiro, a partir do exame da conjuntura política e da história social do ofício, demonstramos como 
se formou o mercado de serviços médicos. Para isso, enfatizamos, no exame da gênese do espaço médico, tanto os processos específicos da luta pela segmentação e competição com outros ofícios e as relações particulares estabelecidas com o Estado e com as famílias dirigentes quanto o surgimento de um corpo de produtores especializados que passou a se dedicar ao ofício e a tirar dele seu sustento (médicos, cirurgiões). Nessas disputas por princípios de organização, classificação e dominação do espaço social, como destacam Bourdieu (2002), Dezalay e Garth (2015), Dubar (2003) e Karpik (2003), os produtores comprometem os recursos acumulados ao longo de sua trajetória e que resultaram de múltiplos investimentos (políticos, profissionais, familiares, econômicos).

Segundo, as ações coletivas dos membros da profissão, a emergência das associações profissionais e o papel que desempenharam como espaços de socialização e convivência entre frações concorrentes da elite dominante. Partimos do princípio de que a formação de uma estrutura organizacional, como instituições e instâncias de consagração específicas (associações profissionais, sociedades médicas, sindicatos, conselhos), permitiu o desenvolvimento de práticas médicas, do controle profissional e da constituição de um monopólio no mercado de cura. O fortalecimento das bases institucionais desempenhou papel fundamental nesse processo de dominação da medicina sobre as outras práticas de cura, sobretudo os hospitais, que passaram a ocupar um lugar central para o desenvolvimento do profissionalismo.

Por fim, analisamos os principais recursos mobilizados pelos produtores para realizar investimento na medicina como profissão. Para isso, tomamos a trajetória de um dos principais protagonistas no processo de institucionalização da medicina em Sergipe: Augusto César Leite. Seu percurso representa um caso exemplar da articulação bem-sucedida entre investimentos políticos, familiares e profissionais.

$\mathrm{O}$ argumento central é de que o projeto profissional - com a criação e expansão do mercado de serviços médicos - e a luta pela segmentação compuseram os sofisticados mecanismos de reestruturação das elites locais. Em um contexto caracterizado pelo sistema da parentela - cuja dinâmica estava fundada no domínio dos proprietários rurais e baseada nos arranjos diversificados entre famílias e afins (aliados políticos, afilhados, amigos) -, a forte rivalidade marcava a competição entre os grupos dominantes. Nessas condições, a organização do espaço profissional por meio da sua institucionalização (hospitais, centros de saúde, associações profissionais, sociedades médicas) constitui-se em um importante recurso nessas disputas, permitindo às frações concorrentes da elite dominante, nas quais os médicos estavam distribuídos, não só a sobrevivência econômica, mas o fortalecimento dos laços, o estabelecimento de vínculos e alianças. Diante desse quadro, para preservar sua posição no espaço do poder, cada vez mais ameaçada pela competitividade, não restou outra saída às elites políticas senão investir em espaços institucionais capazes de possibilitar a formação de novas redes. É nessas condições que o estudo sobre Sergipe pode fornecer como contribuição à literatura acadêmica dos estudos sobre profissões e elites - elementos para compreender as lógicas que fundamentam e estruturam a medicina e suas complexas relações com a política. 


\section{A fragmentação oligárquica e as condições de estruturação do mercado de serviços médicos}

No início do século XX, a medicina clínica era um ofício secundário e não desfrutava de prestígio social e valorização profissional num mercado privado de cura. O curanderismo, a pajelança e as rezas compunham as principais alternativas no tratamento das doenças que, apesar de comuns entre a população rural e entre os mais carentes, faziam parte das concepções de doença e saúde vigentes. O afastamento dessas práticas se manifestou no papel ativo do Estado, que, num primeiro momento, passou a exigir dos praticantes a solicitação de registros, assumindo uma função fiscalizadora intensa e definindo aqueles que estariam aptos a exercer esses ofícios. E, num segundo momento, por meio do código criminal de 1890, classificou como ilegal as denominadas "práticas de magia" (Salgado, 1998).

Além disso, os problemas clínicos não eram priorizados pelos médicos, e o centro das discussões girava em torno do controle e da prevenção de doenças infectocontagiosas que atingiam as regiões rurais e os grandes centros urbanos. Doenças epidêmicas, entre elas febre amarela, dengue, malária e cólera, eram vistas como problemas políticos e com frequência associadas às más condições de higiene e aos meios insalubres, e, por isso, exigiam a participação ativa do governo por meio da higienização e disciplinarização da população. Nessa direção, por intermédio do projeto higienista, Estado e medicina se aliam, e os médicos consolidam sua participação no sistema público de saúde, apresentando-se como profissionais fundamentais (Pereira Neto, 2001; Benchimol, 2000; Coradini, 2005; Edler, 1998; Hochman, 2012).

Formados nas escolas de medicina, os médicos diplomados encontraram na atividade política um espaço aberto de atuação, dedicando seu tempo, à saúde pública (controle de epidemias, febres, diarreias) ou ao Estado, em carreiras eletivas (deputados, senadores, governadores) e na ocupação de cargos públicos (secretário de higiene, delegado de higiene, diretor de departamentos de higiene pública). Além de ser desempenhado por um pequeno grupo com posição econômica elevada, o ofício dependia das relações de base familiar como critério de seleção e recrutamento para a ocupação de tais cargos. Em situações regionais, onde se situavam as faculdades de medicina e as associações profissionais, conforme destaca Coradini (1996), a consagração médica dependeu, além da política, da cátedra e da participação em entidades de classe. Nos demais, como é o caso de Sergipe, a atuação estava associada, exclusivamente, às disputas num mercado de cargos públicos e políticos.

Nessas condições, até o final do século XIX e as primeiras décadas do século XX, os médicos em Sergipe não viviam da clínica médica, mas como chefes políticos locais ocupando cargos ora na estrutura burocrática do Estado (delegados de higiene, professores, diretores) ora em cargos eletivos. O controle de tais postos almejados era inseparável dos alinhamentos políticos que resultavam dos acordos com a oligarquia agrária. Tais acordos dependiam da formação de agrupamentos políticos organizados a partir dos arranjos, muitas vezes incertos e instáveis, entre famílias e afins (aliados políticos, afilhados, amigos). Controlados, fundamentalmente, por proprietários rurais (denominados "coronéis"), esses agrupamentos tinham como característica central um processo de recrutamento político diversificado, que não se baseava exclusivamente no parentesco, mas num sistema que 
incluía uma rede ampla e extensa de parentes (colaterais, por afinidade e descendentes) e amigos. Essas alianças estabelecidas exerciam forte influência nas diferentes esferas da vida social, uma vez que eram elas a exercer o controle sobre todos os postos locais, desde médico, juiz, tabelião até mesmo pároco.

Esses agrupamentos políticos derivavam da união entre parentelas e constituíram-se como mecanismo central de dominação social e princípio de estratificação social que determinavam o sistema de distribuição dos cargos. A parentela representava, portanto, a unidade política menor desse sistema de alianças, cobrindo a vida social dos municípios e estados. Delas se organizavam os agrupamentos políticos e a oligarquia, sua expressão máxima (Candido, 1951; Lewin, 1993; Queiroz, 2006).

Submetido a essas condições, o espaço da medicina, no século XIX, deve sua estrutura à distribuição dos médicos entre parentelas rivais que disputavam cargos num mercado político. O fator de concorrência, portanto, consistia nos recursos políticos que decorriam das redes de relações de base familiar, já que se tratava de alianças entre famílias e amigos/ aliados, para se ter acesso aos cargos. A obtenção desses recursos era condição de entrada nessa competição. Nessas condições, a posição que o médico ocupava no sistema de parentela determinava sua posição e estratégias de luta no espaço da medicina (cargos, tomadas de posição). Assim, as parentelas que ocupavam posições polares, muitas vezes, no espaço da política, opunham-se também em matéria de medicina, conduzindo a rivalidades pessoais entre seus membros.

Do final do século XIX, com a instauração da República, até a Revolução de 1930, Sergipe era controlado por dois grupos políticos que disputavam o domínio oligárquico. "Pebas" e "cabaús" constituíram as principais dissidências políticas que contavam com o apoio de diferentes parentelas e que levaram à emergência de duas grandes oligarquias: ValadãoLobo, apoiada pelos primeiros, e a oligarquia Olimpista, apoiada pelos cabaús. A primeira contou com pelo menos dois médicos que ocuparam o cargo mais alto, o de presidente de Sergipe. A segunda, pelo menos um, em 1911.

Os médicos situavam-se nesse espaço de poder, e a organização do ofício se apresenta, inicialmente, como uma estratégia nos conflitos internos do espaço político. Aqueles que aí disputavam posições passam a utilizar seus ofícios de formação (e de seus descendentes ou aliados) nas oposições internas, com o objetivo de conservar ou transformar sua posição nesse espaço de confronto. Como as parentelas baseavam-se em um forte sistema de rivalidade, as dissidências passaram a se tornar frequentes, conduzindo a intensa fragmentação dos grupos. Visando sustentar sua posição nessa estrutura, os grupos investiram, por um lado, em estratégias de conservação, mantendo o capital (sobretudo capital social e político) acumulado e controlando o acesso ao interior das parentelas, preservando laços e os expandindo quando necessário. Por outro lado, investiram também em estratégias de subversão, manifestada, sobretudo, pelo uso dos títulos acadêmicos e dos ofícios de filhos, sobrinhos e aliados, conduzindo a formas importantes de renovação da condição de elite dirigente.

Os títulos de bacharel (direito, medicina e engenharia) passaram a compor as lutas por distinção, levando tanto à diferenciação interna quanto a trunfos para ocupar novas posições políticas. Aos poucos, com a crescente urbanização da sociedade, a ampliação da máquina 
estatal, a expansão dos serviços públicos e a criação de novos postos, eles se tornaram um dos canais de poder desses chefes políticos locais, como demonstram Petrarca e Oliveira (2016).

No que diz respeito às características sociologicamente pertinentes dos médicos, nessas condições, eles tinham em comum: ser oriundos das frações dominantes, mais especificamente de uma elite rural e agrária distribuída no conflito entre parentelas rivais; ter seguido as fileiras escolares que conduziam as classes dominantes às carreiras políticas; ser recrutados pelas famílias dirigentes para ocupar postos e cargos médicos e políticos; ser formados e treinados pelas mesmas faculdades e voltar-se para a resolução de problemas de saúde pública e não para serviços privados num mercado de cura, conforme descreve Petrarca (2017).

Entretanto, apesar de se constituir como uma elite unitária - em termos de perfil social e formas de treinamento e atuação -, era ao mesmo tempo segmentada e fragmentada, em função da sua distribuição no sistema de parentela. Essa falta de coesão política conduziu a estruturas partidárias instáveis, de curta duração, sobretudo no período republicano, que se tornavam sedes dos agrupamentos políticos e, portanto, suscetíveis aos conflitos.

A forte concorrência no interior desse sistema e sua consequente subdivisão contribuíram para que as elites médicas se organizassem de acordo com essa estrutura. Assim, o que fazia falta aos médicos no século XIX não eram apenas os recursos técnicos (equipamentos, hospitais, tecnologia), mas os meios institucionais capazes de reuni-los em torno de problemáticas comuns e permitir a mobilização de recursos individuais para um projeto coletivo que os unificasse. De forma semelhante às experiências dos estados vizinhos, como a Bahia descrita por Santos (1998), Sergipe estava imerso na "política de facções" que resultava na intensa divisão e instabilidade política.

A criação de instituições médicas, o aparecimento de instâncias de consagração exclusivas aos médicos (associações, sociedades médicas) e a expansão de um mercado de serviços, organizados em torno de um projeto profissional, representaram não só uma renovação nas estratégias das elites dirigentes que se encontravam fragmentadas e divididas pelas rivalidades internas, mas também uma possibilidade de reunir os médicos, antes divididos no confronto entre os agrupamentos políticos. Por meio dos espaços e das estruturas institucionais, eles intensificaram o controle sobre a política e mobilizaram os laços e redes oriundos do seu grupo de origem em prol da organização do ofício.

Portanto, a institucionalização da medicina é reflexo da reestruturação no espaço do poder e da política que conduziu à necessidade de organização em torno de projetos comuns. A posição que os protagonistas da profissionalização passam a ocupar na condução e elaboração do projeto profissional resulta do seu passado social e da sua posição no sistema de parentelas. Tais condições os predispõem a exprimir a necessidade de um mercado de serviços médicos e da institucionalização profissional.

É nas primeiras décadas do século XX que se observa um movimento mais intenso de institucionalização da medicina em Sergipe. Entre as condições que contribuíram para isso está a própria consolidação da República, em 1889, a qual fortaleceu a autonomia dos estados, garantindo a soberania das elites regionais e intensificando o poder dos chefes políticos locais na condução dos municípios dos quais se originavam. Além disso, foi com a República que os serviços de saúde pública, sobretudo os sanitários (vigilância 
epidemiológica, institutos de vacinas e laboratórios), expandiram-se, permitindo aos médicos colocar-se a serviço do Estado (Hochman, 2012). Conforme demonstra Luz (2013), a partir disso, o Estado brasileiro se torna o organizador das instituições médicas - como hospitais, órgãos de assistências, secretarias de saúde - para enfrentar questões de saúde que eram vistas e definidas como problemas públicos. Tais reformas exerceram um impacto nas práticas tradicionais de cura, que passaram a ser consideradas perigosas para a saúde pública, tornando-se alvo de controle policial e sanitário.

A expansão dos serviços de saúde conquistados com a República contribuiu para que, já no final do século XIX, Sergipe contasse com uma inspetoria de higiene, órgão com a função de nomear delegados de saúde para todos os municípios. Contudo, as principais alterações institucionais no espaço médico começam a se desenvolver a partir de 1920, no governo de Graccho Cardoso, o qual contou com forte aliança de um conjunto de médicos locais, dispersos nos já mencionados grupos políticos oligárquicos pebas e cabaús. Se no início do século XX Sergipe dispunha de quatro hospitais públicos distribuídos entre as principais cidades (Aracaju, Estância, Laranjeiras e Rosário) e que funcionavam como casas de acolhimento e caridade, a situação muda drasticamente a partir da década de 1920 com a criação de três instituições que exerceram impacto decisivo na formação de uma cultura e identidade médicas. São elas: Instituto Parreiras Horta, Sociedade de Medicina e Cirurgia de Sergipe e o Hospital Cirurgia.

O Diagrama 1 ilustra as transformações institucionais no espaço da medicina sergipana durante o século XX.

Diagrama 1: Mercado de serviços médicos em Aracaju

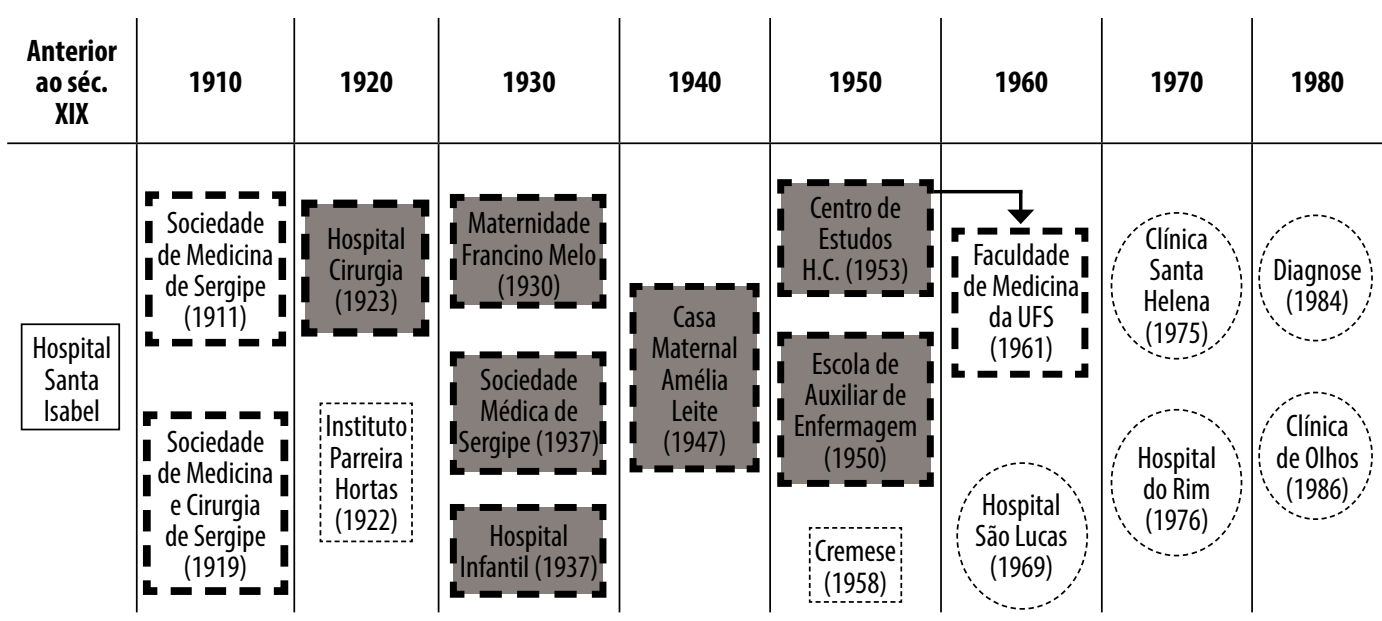

Legenda:

- Quadrado: instituições públicas;

- Todos os pontilhados: médicos como protagonista;

- Pontilhados em negrito: médico Augusto Cesar Leite como protagonista;

- Pontilhados preenchidos: instituições vinculadas ao Complexo Hospitalar de Cirurgia;

- Seta: conexão entre as instituições;

- Círculos: instituições privadas.

Fonte: elaborado pela autora. 
Tal diagrama nos permite identificar as seguintes questões: (1) expansão dos serviços médicos públicos, organizados pelo Estado, após a década de 1920, associada à presença de Carlos Chagas no Departamento de Saúde Pública e à primeira Reforma Sanitária; (2) o protagonismo do médico Augusto César Leite, o qual se torna o organizador dos serviços médicos, controlando o processo de recrutamento e seleção no interior dessas instituições a partir do Hospital Cirurgia; (3) o papel do Hospital Cirurgia na emergência de novos espaços médicos de socialização e de consagração; (4) a formação de duas estruturas organizacionais: públicas e privadas. Até as décadas de 1970 e 1980 as instituições eram fundamentalmente públicas. A partir daí se observa o investimento do corpo médico em espaços privados de cura, com a presença de grandes hospitais e clínicas particulares.

\section{Da política de parentela a caminho do clube: hospitais, institutos e as instâncias de representação profissional}

Uma das grandes dificuldades do sistema de parentela era criar unidade e coesão entre os seus membros devido à intensa facilidade em fazer e desfazer laços. Ao mesmo tempo que esse sistema possibilitava a ampliação dos vínculos, por meio de acordos múltiplos, permitindo aos grupos dirigentes conservar sua posição de dominação, ele dificultava a formação de grupos coesos que se organizassem em torno de um projeto ideológico comum. Como o princípio partidário não se impôs a esses grupos, sua formação dependia exclusivamente de uma política flexível de alianças, mas baseada numa forte rivalidade, o que tornava possível estabelecer novos contatos e romper os já existentes, se assim fosse necessário (Queiroz, 2006). Esse foi um dos fatores que durante muito tempo impediu, sobretudo no caso de Sergipe, a consolidação de associações classistas ou de natureza profissional.

A concorrência entre as parentelas no jogo político e na luta por postos e cargos estatais conduziu à atualização dos recursos e à progressiva expansão dos laços sociais. A organização dos espaços de representação profissional emerge dessa conjuntura, compondo os diversificados mecanismos de renovação dos grupos dominantes. Por um lado, essas instituições funcionaram como espaço de convivência entre grupos rivais, exigindo dos blocos concorrentes certos acordos, como demonstrou Queiroz (2006). Um dos principais objetivos da emergência de associações de classe foi o de fortalecer a solidariedade horizontal das parentelas, ou seja, a relação entre indivíduos do mesmo nível socioeconômico, e enfraquecer a solidariedade vertical (entre os desiguais). Por outro lado, elas promoveram também a emergência de novas formas de consagração profissional, permitindo a formação de uma comunidade com princípios de identificação comuns.

Nessa direção, as instituições representaram uma estratégia de sobrevivência do sistema de parentela, produzindo novas associações entre membros das elites dominantes. Concomitantemente, elas expandiram as redes de relações, proporcionando a formação dos espaços de atuação e representação profissionais, como as entidades médicas e o próprio mercado. Contudo, tal condição foi conquistada com dificuldade e causou a divisão e a formação de novos grupos no controle do jogo político.

A primeira tentativa de organização de uma entidade médica ocorreu em 1910 e teve como protagonistas os médicos Helvécio de Andrade (presidente) e José Rodrigues da 
Costa Dória (presidente de honra), ambos aliados vinculados ao agrupamento político cabaús, centro de apoio da oligarquia olimpista. Apesar da curta existência, ${ }^{1}$ a entidade, que agregou dentistas e farmacêuticos, conseguiu publicar a primeira revista médica do estado. O fracasso na continuidade deve ser compreendido dentro das disputas entre parentelas que compunham o cenário político em Sergipe. No início do século XX, a política sergipana era controlada pelo grupo dos olimpistas, conservadores ligados a Olímpio Campos, que mantinham o controle do Partido Republicano Sergipense (PRS). Num delicado equilíbrio entre parentelas - caracterizadas pela fragmentação em dissidências, o que gerava forte instabilidade -, os grupos oligárquicos, entre eles os olimpistas, disputavam o poder. Esse grupo permanece na liderança do estado elegendo governadores até 1911, com a gestão do médico José Rodrigues da Costa Dória, da parentela dos Dória, de Propriá (Oliveira, 2008).

Helvécio de Andrade, fundador da referida entidade, compunha a parentela de Dória como aliado. De origem social humilde, foi apadrinhado pelo tio materno, padre, tendo condições de concluir seus estudos (secundário e universitário) na Bahia, formando-se em 1886. Sua carreira tem início no interior de Sergipe, mas, dadas as dificuldades em se inserir na cena médica, controlada pelas famílias, mudou-se para São Paulo, onde exerceu os cargos de inspetor sanitário, atuando no combate à febre amarela, inspetor geral de ensino público e médico adjunto do Exército. Ao retornar a Sergipe, já no início do século XX, instalou-se no município de Maruim, onde atuou como médico (clínico e cirurgião) e político, escrevendo em jornais e fundando o Partido Revisionista juntamente com um padre da cidade. Nesse contexto, apoia a candidatura de Costa Dória ao governo de estado e solidifica sua conexão com esse grupo. Esse vínculo lhe rendeu o cargo de lente da Escola Normal e diretor da Instrução Pública, com forte intervenção e gerência na relação entre a questão pedagógica e a higienização dos corpos (Guaraná, 1925; Silva, 2007).

Enquanto Helvécio atuava na medicina higienista, ocupando cargos estatais, Costa Dória atuava no controle do Hospital Santa Isabel, então o espaço médico-cirúrgico mais importante do estado. Por meio dessas instituições, eles controlavam o acesso aos postos. Mas a forte rivalidade entre as parentelas se manifestou também no interior da sociedade médica, gerando grandes dificuldades em mantê-la funcionando num momento de intensa competitividade e minando as iniciativas em unir o grupo em torno de um projeto profissional.

Outro exemplo nessa direção foi a criação do Instituto Parreira Hortas, importante centro de combate a epidemias no estado. Criado em 1922, o instituto compõe a expansão dos serviços sanitários promovidos tanto pela federação quanto pelos estados em todo o país e surgiu com uma função similar à do Instituto Oswaldo Cruz, fundado em 1900, no Rio de Janeiro (Silva, 2007). Este último seguia o modelo do Instituto Pasteur em Paris e tinha como principal foco o controle de epidemias, o preparo e a distribuição de soros e vacinas, voltando-se para as campanhas de saneamento, para o ensino, com forte impacto na formação médica, e para a pesquisa (Sanglard, 2007). Tal instituto em Sergipe contribui para aglutinar os médicos, tornando-se importante espaço de discussões sobre as chamadas "febres do Aracaju". De início, ele se consolidou como espaço de produção de saberes técnicos e científicos em tornos das febres, dos agentes etiológicos e da produção de vacinas. Um 
dos principais impactos foi o de esclarecer que a febre tifoide era a principal manifestação das chamadas "febres do Aracaju".

Contudo, apesar de seu papel na formação de um espaço médico, o instituto representava as investidas do governo federal na saúde pública e não era uma autarquia estadual, deixando pouco espaço para as elites políticas locais disputarem o controle sobre os postos. É somente em 1956 que ele passa a integrar a administração indireta do estado, fornecendo mais autonomia na gerência da instituição (Silva, 2007).

A centralização dos serviços sanitários, promovida pela República, enfrentou forte resistência em Sergipe e se tornou um dos principais motivos de conflito, pois os ocupantes dos cargos anteriores vinculados ao estado e município, como delegados de higiene, foram exonerados, e as nomeações passaram para o controle da federação. Um exemplo nessa direção está nos confrontos entre o governo do estado e o Departamento Nacional de Saúde. Em 1922, o governador Graccho Cardoso solicitou acordo com o Departamento Nacional de Saúde Pública, chefiado na ocasião por Carlos Chagas, para assumir os serviços sanitários estaduais e nomeou seu irmão, Eleyson Cardoso, médico, exonerando o que estava no lugar. O Departamento Nacional não aceitou a nomeação e indicou o nome de Phoncio Serpa, sanitarista discípulo de Oswaldo Cruz. Phoncio assumiu e, de início, estabeleceu um conjunto de medidas sanitárias. Contudo, durante uma das suas viagens ao Rio de Janeiro, Serpa deixou em seu lugar Eleyson Cardoso como substituto. Este último aproveitou a oportunidade e nomeou um aliado local, Carlos Menezes, como chefe. Apesar de Serpa ter recuperado o cargo no seu retorno, a atitude provocou desavenças com o governo federal, e o desfecho final foi o rompimento do contrato entre estado e federação (Santana, 2001; Silva, 2007).

Aconselhado por um grupo de médicos aliados que estavam querendo construir um novo hospital, um ano após o confronto, o governo do estado retomou a parceria, acatando a centralização federal. Em 1926, o contrato foi novamente suspenso e ressurgiu a Repartição Estadual, que comandou as ações sanitárias no estado até 1930. Ligada diretamente à Secretaria-geral do governo, a repartição teve Eleyson como seu primeiro diretor.

Uma nova tentativa em torno do projeto profissional foi feita em 1919, com a criação da Sociedade de Medicina e Cirurgia de Sergipe. Organizada e liderada por outro grupo de médicos, em geral cirurgiões, teve forte presença no jogo político, exercendo papel importante na definição das políticas de saúde e na pressão para criação de um novo hospital no estado: Hospital Cirurgia. Esses médicos faziam parte de grupos familiares aliados que se tornaram rivais de Costa Dória e apoiavam o então governador do estado, Gracco Cardoso. E, em vez de disputar o controle do Hospital Santa Isabel, voltaram-se para a criação de um novo hospital, controlado exclusivamente por médicos (Leite, 2008; Santana, 2001).

Um exemplo associado às dificuldades de convivência entre as parentelas rivais, que as associações contribuíram para criar, está na disputa entre Helvécio de Andrade e Augusto César Leite. O confronto entre eles revela as consequências dos conflitos para a formação de um espaço profissional. Helvécio e Augusto se envolveram, nos idos de 1918, em uma querela médica no tratamento de um paciente que veio a falecer. O caso ganhou proporções destacadas na imprensa local, levando a desgaste jurídico entre eles e revelando as tensões políticas em que a medicina estava submersa. As trocas de acusações pela responsabilidade 
do diagnóstico e respectivo tratamento levaram Augusto César Leite a mobilizar sua rede de colegas profissionais - que gravitavam em torno da Sociedade de Medicina e Cirurgia de Sergipe - e aliados políticos do seu grupo familiar na defesa de sua autoridade médica. Uma das suas iniciativas foi a de proferir uma conferência na Biblioteca Pública com a presença de autoridades locais, o governador e líderes da Igreja. Além disso, a referida associação médica se reuniu e produziu uma moção de apoio a Augusto César Leite, afirmando que "é destituída de toda razão científica ou de ordem clínica a alegação que quis ver no desfecho banal de uma afecção renal preexistente um episódio de intoxicação medicamentosa, ou de erro de conduta terapêutica" (Figueiredo, 1986, p.382). Segundo Figueiredo, tanto os médicos da Sociedade de Cirurgia como a imprensa local - de propriedade de aliados de Augusto César Leite - assumiram posição ao seu lado.

As instituições funcionavam como espaço de consolidação dos agrupamentos políticos, e a necessidade de reunir os membros em torno do ofício esbarrava nos conflitos e nas rivalidades existentes. Tendo como forte articulador Augusto César Leite, a entidade se converteu em um espaço importante de influência do seu grupo no processo político e agregou quase a totalidade dos médicos do estado (Santana, 2001). Com isso, permitiu aos seus membros a formação e o acúmulo de vínculos políticos que possibilitaram uma aproximação com o Estado e com a esfera política, de modo geral.

Um dos principais efeitos dessa instituição foi a pressão feita sobre o governo para a criação do Hospital Cirurgia (Figueiredo, 1986). Fundado em 1923, o referido hospital representou uma das primeiras iniciativas de coesão e também uma mudança importante no lugar dessa instituição para a autoridade médica. De um lado, diferente dos demais existentes no estado, o Cirurgia se tornou um estabelecimento de cura e de assistência à saúde, e não de caridade ou ajuda social, além de ser um espaço de formação de saberes, com forte teor educativo. É nele que se forma a "mentalidade clínica", adquirida pela experiência no trato com a doença e com o paciente. De outro, ele representou o controle dos hospitais pelos médicos. A medicalização dos hospitais se tornou essencial para o processo de profissionalização da medicina, uma vez que, a partir dela, os hospitais passaram a se tornar espaço de realização da prática médica, sobretudo a prática cirúrgica, seguindo os moldes do modelo francês.

Na falta de uma faculdade ou de um centro de formação de saber, o hospital se tornou importante espaço de formação e uniu os médicos com pretensões na definição de um saber constituído a partir dos problemas regionais. Além disso, o Hospital Cirurgia se tornou o catalisador desse processo de institucionalização, constituindo-se como espaço que aglutinou um conjunto de mudanças no ofício médico. É de dentro dele que emergem pelo menos seis novas instituições médicas no estado: Maternidade Francino Melo; Hospital Infantil; Casa Maternal Amélia Leite; Centro de Estudos do Hospital Cirurgia; Sociedade Médica de Sergipe; Escola de Auxiliar de Enfermagem (Diagrama 1).

Logo após a instauração e o funcionamento do Cirurgia, em 1926, a associação que lhe serviu de estímulo foi extinta. Entre as principais explicações apresentadas para o fim dessa entidade está a de que seus representantes passaram a ocupar os principais postos políticos (eletivos e não eletivos) e profissionais disponíveis no estado, o que demandava energia e tempo (Figueiredo, 1986; Leite, 2008). Concentrando-se no Hospital Cirurgia, 
eles ampliaram a possibilidade de intervenção política e conquistaram homogeneidade interna, condições fundamentais para a criação de uma nova entidade, a Sociedade Médica de Sergipe (Somese), em 1937. Diferente da entidade anterior, essa representou o começo de organização de uma comunidade médica coesa e de redes de base profissional.

Nessas condições, o associativismo médico sergipano só pôde, de fato, ocorrer a partir do momento em que os médicos consolidaram a formação de um grupo coeso de base profissional, dentro do Hospital Cirurgia, capitaneado por Augusto Cesar Leite, e com forte intervenção na política estatal. Esse grupo que emerge e se solidifica-constituído pelas redes de base profissional oriundas da atuação em espaços médicos (hospitais, cargos públicos) - funda a Somese, em 1937. Seu primeiro presidente, Augusto César Leite, permanece no cargo por 12 anos, até 1949. É, portanto, no final da década de 1930, com a fundação dessa nova entidade, que essa consolidação se torna possível e as redes profissionais se convertem em capital político.

A forte competitividade entre as parentelas no jogo político ocasionou, por um lado, a fragmentação e formação de dissidências entre grupos muitas vezes pertencentes à mesma oligarquia. Por outro, fez com que as frações desses grupos dominantes tivessem que lançar mão de recursos cada vez mais diversificados para vencer a concorrência. Nessa disputa, as associações e entidades de classe funcionaram como mecanismo de competição e diferenciação, o que resultou em estruturas institucionais múltiplas, instáveis e de curta duração. Desse modo, a rivalidade entre os grupos e sua divisão se tornou também um dos principais obstáculos para a constituição de relações institucionais duradouras.

A emergência de uma entidade capaz de agregar a categoria em torno de interesses comuns só pôde acontecer a partir do momento em que determinadas frações das elites se uniram a fim de ampliar suas formas de articulação e sobreviver às transformações do espaço político. Como parte das suas estratégias de reprodução, essas elites mobilizaram seus vínculos de natureza profissional e investiram intensamente na formação dos espaços de consagração profissional (sociedades, associações, hospitais), centralizando as redes de acesso à medicina, antes dispersas e fragmentadas. É nesses espaços que a amizade profissional é fortalecida e as redes profissionais são ampliadas e consolidadas. Uma das principais consequências disso foi a transformação das entidades de sedes de parentelas em "clubes", agregando indivíduos que tinham em comum seus ofícios e adquirindo importância como forma de inserção em novas redes.

Assim, aos poucos, a parentela como um modo de dominação tradicional, fundamentada em vínculos entre agrupamentos familiares e alianças políticas inconstantes, cedeu lugar a um modo de dominação diversificado, baseado em redes profissionais de longo alcance. A amizade profissional - que emerge como recurso importante desse novo modo de dominação - muda o processo de recrutamento das elites médicas, que passa a depender cada vez mais dos vínculos obtidos nos espaços de atuação profissional.

As décadas seguintes experimentaram um aumento significativo de instituições marcadamente médicas, controladas e administradas pelos médicos. O desenvolvimento e a expansão das instituições tiveram um impacto na afirmação coletiva de um status e na formação de uma "comunidade" médica, com princípios de identificação e legitimação organizados a partir do ofício. Por meio das atividades realizadas nesses espaços (reuniões, 
debates, cirurgias, tratamento de doenças), os médicos, antes divididos nos agrupamentos políticos, tiveram que conviver. Assim as instituições passam a delimitar a existência de um grupo com uma função específica que, por meio da organização desses espaços e das atividades que neles ocorrem, impõe uma determinada autoridade no mercado da cura. É dentro desses grupos que esses profissionais definem seus serviços como especiais, em detrimento de outros, construindo e impondo sua autoridade cultural, social e também política.

Em consonância com isso, essas instituições, que funcionam também como espaços de consagração profissional e social, promoveram um deslocamento do capital de notoriedade: antes definido exclusivamente pela inserção nas parentelas, agora passa a também sofrer a concorrência, com a inserção em espaços associados à prática médica. $\mathrm{O}$ fortalecimento desses espaços de atuação profissional contribuiu para a manutenção das relações de dominação, uma vez que serviu como estratégia para evitar o declínio de muitos agrupamentos políticos que enfrentavam a fragmentação.

\section{Das redes de base familiar às redes profissionais: a trajetória de Augusto César Leite}

O médico Augusto César Leite ocupa a posição de protagonista no processo de institucionalização da medicina em Sergipe, e seus investimentos, tanto políticos quanto profissionais, representam as mais importantes iniciativas de formação de redes coesas e duradouras. Mas a que se deve tal protagonismo? E como foi possível construir coesão num cenário de intensa fragmentação e divisão?

É nesse sentido que a análise da trajetória desse profissional permite compreender como sua base de alianças lhe conferiu protagonismo na organização do mercado de serviços médicos. Tal base estava sustentada, de um lado, pela posição que ocupava no sistema de parentela, de outro, nas redes profissionais que passa a construir com a emergência dos espaços de atuação profissional. O intenso investimento nas alianças a partir da prática médica ampliou sua atuação, expandindo suas redes e exercendo controle sobre o recrutamento médico no estado.

Sua trajetória se caracteriza pela intensa articulação entre medicina e política, investindo ao mesmo tempo em instâncias de representação e consagração médicas e na carreira política como senador. Formado em 1909 pela Faculdade de Medicina do Rio de Janeiro, era filho de um chefe político local que chegara a intendente municipal. Sua família era proprietária de engenho, considerado de médio porte para o período, e vinculada à parentela dos Rollemberg por meio de alianças matrimoniais e da amizade política. Seu pai, no seu segundo consórcio, intensifica os vínculos com esse grupo familiar, casando com a prima da primeira esposa (falecida) e neta do barão de Japaratuba (Gonçalo Acioli de Faro Rollemberg).

Das posições ocupadas no início da carreira, manteve as características do período: postos estatais (professor da cátedra de higiene geral do colégio Ateneu Sergipense e membro do Conselho de Instrução Pública), postos políticos (deputado, senador) e médico-cirurgião (Hospital Santa Isabel). Seu duplo investimento (político e profissional) se manifestou também no acúmulo de qualificação profissional, manifestada na realização de estágios fora 
do país. Sua primeira experiência internacional foi um estágio feito na França, e a segunda, nos EUA (Santana, 2009). Tal circulação internacional lhe garantiu legitimidade cultural num contexto de forte concorrência entre os grupos, ao mesmo tempo que o diferenciou dos médicos locais cujo investimento restringia-se a Sergipe.

Pertencer ao espaço da medicina nesse momento era se confrontar, de um lado, com um sistema de distribuição de cargos e postos que dependia de elevado capital social decorrente das redes de alianças entre as famílias. De outro lado, era se ver diante dos desafios da prática médica que resultavam tanto da baixa aceitação desse profissional, por parte da sociedade mais ampla, para resolver problemas de saúde quanto dos espaços institucionais de atuação. Nessas condições, alguns indivíduos se tornaram cruciais para a definição da carreira médica e política de Augusto César leite, uma vez que permitiram conectá-lo às estruturas das relações.

A primeira figura importante foi o irmão Sílvio Leite, também médico, que integrava a parentela dos Leite, de Riachuelo. Os Leite, de Riachuelo - como família que, aliada a outras, passa a constituir um bloco fundamental para a sobrevivência política, social e econômica -, emergem com a posse de engenhos nas cidades de Laranjeiras e Riachuelo, polos centrais produtores de açúcar do estado. Um dos principais nomes da família foi o capitão Gonçalo Rabelo Leite (bisavô), proprietário do engenho Tartaruga, em Laranjeiras. Importante chefe político local do Partido Liberal foi assassinado, em 1852, pelos herdeiros do seu rival Cavalcanti, do município de Itabaiana, numa clássica luta de famílias. O caráter fragmentário da terra gerava a necessidade constante de alianças, o que contribuiu para que as brigas de famílias em Sergipe não durassem mais que duas gerações. Os Leite, como parentela, constituem exemplo da importância dos grupos de base familiar na política municipal e estadual.

As gerações seguintes não mantiveram a rivalidade e se acomodaram nesse espaço por meio do investimento em alianças cada vez mais múltiplas. Fator importante nesse aspecto foi o casamento de Francisco Rabelo Leite, pai de Augusto César Leite, e Maria Rollemberg, herdeira de vários engenhos na região e neta do barão. Esse matrimônio ampliou as redes de base familiar e permitiu conectar os Leite com os Rollemberg, uma das mais importantes famílias proprietárias de engenho no estado. Desse primeiro matrimônio, Francisco teve três filhos, entre eles Sílvio Leite e Márcia Leite. Viúvo, casa-se pela segunda vez com a prima da primeira mulher. Esse casamento fortaleceu a solidariedade horizontal, valorizando os laços de parentesco entre as famílias e consolidando as alianças. Desse segundo matrimônio nascem dois importantes nomes da política sergipana: Augusto César Leite e Júlio Leite (Leite, 2008).

A geração dos irmãos de Augusto César intensificou e ampliou as alianças familiares. Por um lado, manteve a relação com os Rollemberg por meio do casamento entre tios e primos. Por outro lado, conectou "os Leite" com diferentes grupos, como os Franco e os Prado (Dantas, 2004). Sílvio Leite, no seu primeiro casamento, fortaleceu as alianças endogâmicas e, no segundo, as exogâmicas. Médico, fundou o Hospital de Caridade da cidade, que hoje recebe seu nome, fixou-se no município de Riachuelo, base política da família, onde atuou como delegado de higiene, pecuarista e político (Guaraná, 1925). Assim, quando Augusto César Leite ingressou na carreira médica e política, sua rede de 
base familiar já o conectava às elites sergipanas que tentavam controlar os postos políticos via municípios. Com o irmão, começam as primeiras experiências profissionais tanto na medicina quanto na política.

A segunda figura importante foi o desembargador Simeão Teles de Meneses Sobral aliado político da sua família que compunha a "parentela dos Rollemberg" -, presidente do Hospital Santa Isabel, que o convidou para ingressar no corpo clínico do referido hospital. Esse personagem era tio do médico Gonçalo Rollemberg, o que conecta Augusto César Leite à família Rollemberg e seu grupo de aliados, que eram os que controlavam os postos na região. É dentro desse hospital que Augusto César Leite fortalece os vínculos profissionais, estabelece novas amizades e fomenta a ideia de criação de um novo hospital na cidade de Aracaju que deveria ser administrado por médicos, e não mais por políticos, como era até então. O Hospital Santa Isabel funcionou, nesse contexto, como espaço importante de aglutinação dos médicos, contribuindo tanto para a socialização médica quanto para a formação das redes profissionais.

A terceira figura influente na rede de relações de Augusto foi o irmão Júlio Leite. $\mathrm{O}$ casamento do irmão com a filha do dono da Usina Pedras (Gonçalo das Pedras), a mais importante do estado, também proprietário da maior indústria têxtil de Sergipe, fortalece os laços entre sogro e genro e permite a extensão das alianças entre famílias. Júlio Leite, que era bacharel em direito, intensifica sua atuação na política pela relação com o sogro, tornando-se delegado de polícia, ocupando vários cargos estatais (chefe de polícia, inspetor escolar, diretor de serviços de água e saúde) até se tornar secretário-geral do estado e senador da República (Leite, 2008; Guaraná, 1925; Santana, 2009). Dessa união entre irmãos, sogro e genro nasce um novo agrupamento político denominado União Republicana de Sergipe (URS), coordenado por Augusto César Leite e que tinha como órgão oficial o jornal O Estado de Sergipe (Dantas, 2004).

Tais relações foram fundamentais para fornecer os recursos materiais para organização do mercado de serviços de saúde pública. A criação do Hospital Cirurgia e da Maternidade Francino Melo, ambos públicos, contaram com o patrocínio dos aliados de Júlio Leite (2008). Está ainda vinculada às suas redes a criação de outras instituições de saúde pública: Hospital Infantil, Centro Materno Infantil, Casa Maternal Amélia Leite.

Um quarto grupo de indivíduos também exerceu papel importante na sua carreira, permitindo ampliar suas bases e alianças. Destacam-se aqui os aliados profissionais, cuja base das relações é formada dentro dos espaços de atuação médica, como hospitais e as instâncias de representação. Esse processo de ampliação das bases tem início dentro do Hospital Santa Isabel, onde construiu as alianças fundamentais para a fundação da Sociedade de Medicina e Cirurgia de Sergipe, em 1919. A participação na fundação dessa entidade, junto com os colegas Francisco Pimentel Franco, do Hospital Santa Isabel, e Eronildes Carvalho, diretorgeral de Higiene e Saúde Pública do estado, permitiu-lhe ocupar uma posição importante na liderança da comunidade médica, fundamental para a criação do Hospital Cirurgia. É, portanto, a partir de sua atuação no Hospital Santa Isabel e na Sociedade Médica que ele intensifica a amizade profissional que lhe permite conectar-se a diferentes parentelas e criar novas formas de vínculos em torno da medicina. Dessa relação nasce um importante convite para participar de um jantar com o governador Gracco Cardoso. O jantar, que 
reuniu Augusto César Leite e os amigos médicos Berilo Leite ${ }^{2}$ e Eleysson Cardoso (irmão do governador), tornou-se um evento-chave na criação do Hospital Cirurgia, visto que representa um acontecimento determinante no compromisso firmado pelo governador sobre a criação de um novo hospital.

Assim, ele passa a exercer um papel significativo na articulação dos médicos e na institucionalização da medicina no estado, contribuindo para criação de hospitais, maternidades, centros médicos e associações profissionais. Um dos efeitos disso foi a emergência das estruturas organizacionais de saúde pública, como hospitais e clínicas, e a criação de papéis ocupacionais.

Essas múltiplas alianças o consagraram como liderança médica e política. Com a União Republicana de Sergipe, em 1935, Augusto elegeu-se senador; o médico Eronildes Carvalho (aliado profissional e político), governador; e o irmão Júlio Leite, secretário-geral do governo. É na gestão de Eronildes que Augusto César Leite inaugura o Hospital Infantil, importante anexo construído junto ao Cirurgia. Nesse contexto, suas alianças lideraram vários cargos: o primo, também médico, Moacir Rabelo Leite, assume a direção do Banco Mercantil de Sergipe; vários cargos de interventores municipais são ocupados por aliados: em Maruim, João Feitosa (funcionário do sogro de Júlio Leite) se torna interventor; em Japaratuba, o concunhado de Júlio Leite, e, em Aracaju, Godofredo Diniz, velho aliado. Assim, a parentela "Leite" ocupa os principais postos até os anos 1960-1970 investindo amplamente nas redes de base familiar e ampliando progressivamente para as redes de base profissional. Eronildes permanece como governador até 1941 e, em 1947, é eleito o filho de Sílvio Leite, sobrinho de Júlio e Augusto (Dantas, 2004).

A formação de um mercado de serviços médicos está marcada pela interseção entre as redes profissionais estabelecidas no interior dos primeiros espaços de socialização médica e o investimento na política. Os profissionais que se situam nesse contexto representam uma geração que poderíamos denominar "intermediários profissionais", não só por fazer a conexão, como a geração anterior, mas também porque eram detentores de códigos, informações e, sobretudo, redes de relações que foram mobilizadas para expansão dos mercados profissionais. A concorrência entre as parentelas no controle do jogo político e na luta por postos e cargos estatais, que se ampliou no contexto da República, levou à atualização dos recursos e à progressiva expansão dos laços sociais. Essa diversificação foi essencial para garantir uma posição no bojo da "elite dirigente". Por circular com facilidade, devido ao acúmulo de funções (senadores, médicos, burocratas) e recursos decorrentes disso, estabelecendo contatos e combinando vínculos, eles se tornaram agentes-chave, peças fundamentais na formação de um mercado médico.

Assim, Augusto César Leite, misto de médico e chefe político local, deve sua influência a um conjunto de aliados que envolveu parentes, aliados políticos e laços profissionais. Suas alianças demonstram que as conexões de base familiar continuaram importantes, e onde esses laços já não mais ofereciam garantias, uma alternativa aberta foi a amizade política, constituída na faculdade de medicina e nos espaços de atuação profissional. Em torno do mercado médico vão se constituindo novas formas de recrutamento político e alianças. Além disso, a diversificação econômica do grupo, investindo ao mesmo tempo na indústria, nos mercados profissionais e nos cargos estatais, permite a essas elites dirigentes 
sua reorganização política. A amizade profissional é conectada à política, fortalecendo suas bases e expandindo horizontalmente suas relações.

Portanto, é o conjunto dos vínculos que Augusto César Leite agrega, seu alto capital relacional, que permite a participação intensa na criação das instâncias de representação profissional e dos espaços de atuação médicos. Tais condições lhe permitiram acumular vários tipos de recursos (circulação internacional, prática médica e política) fundamentais para a criação das principais instituições médicas, desde aquelas voltadas para a representação profissional (associações, sociedades médicas) até as de formação e treinamento (centro de estudos, faculdades) e espaços de atuação prática (hospitais, clínicas, maternidades).

\section{Considerações finais}

Este artigo demonstrou que o processo de consolidação da medicina em Sergipe deve ser compreendido como parte das mudanças realizadas para a reestruturação das elites agrárias locais a fim de evitar o declínio de sua condição. A forte rivalidade produzida no interior das parentelas e a sua fragmentação decorrente dos conflitos conduziram à expansão dos vínculos e a um direcionamento para os laços produzidos a partir do universo profissional.

Num primeiro momento, eram as parentelas que, como grupo, permitiam o acúmulo de capital social e o reconhecimento, fornecendo os critérios de recrutamento e seleção de médicos, políticos, juízes. Num segundo momento, as redes profissionais, consolidadas no pertencimento a associações e sociedades, e o próprio espaço de atuação, como os hospitais, regularam o recrutamento e o acesso ao trabalho. Uma vez que os médicos consolidaram uma clientela e um mercado de serviços, formaram um agrupamento com o poder de excluir os concorrentes e que tem nas redes, sejam elas formais (associações, sociedades) ou informais (amigos, conhecidos, parentes), importantes mecanismos de controle do conflito e da competição.

O surgimento de um corpo de produtores especializados que passou a se dedicar ao ofício e a tirar dele seu sustento (médicos, cirurgiões) foi uma condição fundamental para a consolidação da medicina; contudo, não foi suficiente, uma vez que os médicos estavam submetidos às dissidências das parentelas. Uma segunda condição foi necessária: a formação de uma estrutura organizacional, como instituições e instâncias de consagração específicas (associações profissionais, sociedades médicas, sindicatos, conselhos), capaz de permitir o desenvolvimento de práticas médicas, o controle profissional, a constituição de um monopólio no mercado de cura e, por fim, a expansão de um mercado.

Essas transformações delimitaram um espaço de atuação, instaurando e mantendo novas relações de dominação. Além disso, a criação e a consolidação de instituições - cujo objetivo era o de reunir os médicos em torno de um projeto profissional comum, trouxe impactos importantes, tais como: a formação de uma cultura profissional por meio da sociabilidade e das atividades desenvolvidas nessas instituições; a promoção de novos espaços de consagração profissional destinados exclusivamente aos médicos; a renovação dos recursos capazes de promover ascensão profissional. Isso porque as instituições promovem a emergência de um novo fator de concorrência, que é a inserção em instâncias exclusivas (hospitais, associações, sindicatos). 
Essa investigação certamente não se restringe a Sergipe e ao Brasil e pode nos provocar a superar a falsa oposição entre a construção de um mercado de postos profissionais e os investimentos na esfera política.

\section{NOTAS}

${ }^{1}$ A entidade durou apenas um ano.

${ }^{2}$ Vinculado à parentela dos Leite, de Estância.

\section{REFERÊNCIAS}

ABBOTT, Andrew.

Écologies liées: à propôs du système des professions. In: Menger, Pierre Michel (Dir.). Les professions et leurs sociologies. Paris: Editions de la Maison des Sciences de L'Homme. p.29-50. 2003.

ABBOTT, Andrew.

The system of profession. Chicago: The University of Chicago Press. 1988.

BENCHIMOL, Jayme.

A institucionalização da microbiologia e a história da saúde pública no Brasil. Ciência e Saúde Coletiva, v.5, n.2, p.265-292. 2000.

BOURDIEU, Pierre.

A produção da crença. São Paulo: Zouk. 2002.

CANDIDO, Antonio.

The Brazilian family. In: Smith, Thomas Lynn; Marchant, Alexander (Ed.). Brazil, portrait of half a continent. New York: The Dryden Press. p.281312. 1951.

CHAMPY, Florence.

La sociologie des professions. Paris: Presses Universitaires de France. 2009.

CORADINI, Odaci.

A formação da elite médica, a Academia Nacional de Medicina e a França como centro de importação. Revista Estudos Históricos, v.1, n.35, p.3-22. 2005.

CORADINI, Odaci.

Grandes famílias e elite profissional na medicina no Brasil. História, Ciências, Saúde - Manguinhos, v.3, n.3, p.425-466. 1996.

DANTAS, Ibaré.

História de Sergipe: República (1889-2000). Rio de Janeiro: Tempo Brasileiro. 2004.

DEZALAY, Ives; GARTH, Bryant.

A construção jurídica de uma política de notáveis: o jogo duplo da elite do Judiciário indiano no mercado de virtude cívica. Revista Pós Ciências Sociais, v.12, n.23, p.37-59. 2015.

DUBAR, Claude.

Sociologie des groupes professionnnels en France: um billan perspective. In: Menger, Pierre Michel (Dir.). Les professions et leurs sociologies. Paris: Editions de la Maison des Sciences de L'Homme. p.51-70. 2003.

EDLER, Flávio.

A medicina brasileira no século XIX: um balanço historiográfico. Asclepio, v.50-52, p.169186. 1998.

FIGUEIREDO, Ariosvaldo.

História política de Sergipe: do golpe de 15-11-1889 ao golpe de 31-3-1964. v.1. Aracaju: Sociedade Editorial de Sergipe. 1986.

FREIDSON, Eliott.

Professional dominance: the social struture of medical care. New Jersey: Transaction. 2007.

GUARANÁ, Armindo.

Dicionário biobibliográfico sergipano. Rio de Janeiro: Ponghetti. 1925.

HOCHMAN, Gilberto.

A era do saneamento: as bases da política de saúde pública no Brasil. São Paulo: Hucitec. 2012.

KARPIK, Lucien.

Les professions et la sociologie historique. In: Menger, Pierre Michel (Dir.). Les professions et leurs sociologies. Paris: Editions de la Maison des Sciences de L'Homme. p.70-91. 2003.

LEITE, Ricardo.

Júlio Leite: o chefe invisível. Aracaju: Triunfo. 2008.

LEWIN, Linda.

Política e parentela na Paraíba: um estudo de caso da oligarquia de base familiar. Rio de Janeiro: Record. 1993.

LUZ, Madel.

As instituições médicas no Brasil. Porto Alegre: Rede Unida. 2013. 
OLIVEIRA, Yolanda Dantas.

Educação da criança à luz da ciência: a contribuição de Helvécio de Andrade em Sergipe (1911-1935). Tese (Doutorado em Educação) Pontifícia Universidade Católica de São Paulo, São Paulo. 2008.

PEREIRA NETO, André de Faria. Ser médico no Brasil: o presente no passado. Rio de Janeiro: Editora Fiocruz. 2001.

PETRARCA, Fernanda Rios.

De coronéis a bacharéis: reestruturação das elites e medicina em Sergipe. Revista Brasileira de História, v.37, n.74, p.2-24. 2017.

PETRARCA, Fernanda Rios; OLIVEIRA, Wilson José.

Os estudos de elites no Brasil: um ensaio crítico sobre a produção recente. In: Reis, Eliana; Grill, Igor (Org.). Estudos sobre elites políticas e culturais. v.2. São Luís: Edufma. 2016.

QUEIROZ, Maria Isaura Pereira.

Coronelismo numa interpretação sociológica. In: Fausto, Bóris et al. História da civilização brasileira. v.8. Rio de Janeiro: Bertrand Brasil. p.172-214. 2006.
SALGADO, Tânia.

Barbeiros, sangradores e curandeiros no Brasil (1808-1828). História, Ciências, Saúde Manguinhos, v.5, n.2, p.349-372. 1998.

SANGLARD, Gisele.

Hospitais: espaços de cura e lugares de memória de saúde. Anais do Museu Paulista, v.15 n.2, p.257-289. 2007.

SANTANA, Antônio.

Dicionário biográfico de médicos de Sergipe: séculos XIX e XX. Aracaju: Academia Sergipana de Medicina. 2009.

SANTANA, Antônio. As febres do Aracaju: dos miasmas aos micróbios. Aracaju: Edição do Autor. 2001.

SANTOS, Luiz A. de Castro.

As origens da reforma sanitária e da modernização conservadora na Bahia durante a Primeira República. Dados, v.41, n.3, s.p. 1998.

SILVA, Henrique Batista.

História da medicina em Sergipe. Aracaju: J.

Andrade. 2007.

WILENSKY, Harold.

The professionalization of everyone? American Journal of Sociology, v.70, n.2, p.137-158. 1964. 